\title{
Doping of 2-Cl-PANI/PVC films by exposure to UV, $\gamma$-rays and e-beams
}

\author{
U.A. Sevil ${ }^{a}$, O. Güven ${ }^{b}$, Ö. Birer ${ }^{c}$, Ş. Süzer ${ }^{c}{ }^{c *}$ \\ ${ }^{a}$ Ankara Nuclear Research and Training Centre, Beşevler, Ankara 0600, Turkey \\ ${ }^{\mathrm{b}}$ Department of Chemistry, Hacettepe University, Ankara 06532, Turkey \\ ${ }^{c}$ Department of Chemistry, Faculty of Science, Bilkent University, Ankara 06533, Turkey
}

Received 1 October 1999; accepted 4 October 1999

\begin{abstract}
2-Chloro-polyaniline (2-Cl-PANI) is chemically prepared in its non-conducting (Emeraldine Base, EB) form and dissolved together with polyvinylchloride (PVC) in THF for casting into thin $(10-50 \mu \mathrm{m})$ composite films. The electrical conductivity of these films increases by more than four orders of magnitude (from $10^{-6}$ to $10^{-2} \mathrm{~S} / \mathrm{cm}$ ) when they are exposed to UV, $\gamma$-rays and e-beams. This is attributed to the dehydrochlorination (loss of $\mathrm{HCl}$ ) of $\mathrm{PVC}$ by exposure to energetic particles and subsequent doping of the 2-Cl-PANI (i.e., conversion to Emeraldine Salt, ES) by the in-situ-created $\mathrm{HCl}$. The doped films can also be returned to their undoped form by further exposure to $\mathrm{NH}_{3}$ vapours. The UV (or other particles)-induced doping $/ \mathrm{NH}_{3}$ undoping cycles can be repeated several times until almost total dehydrochlorination of the PVC matrix. UV-Vis-NIR, Fourier transform infrared (FTIR) and X-ray photoelectron spectroscopic (XPS) techniques are employed to follow the changes in the composite films upon doping by exposure to these energetic particles. (C) 2000 Elsevier Science S.A. All rights reserved.
\end{abstract}

Keywords: 2-Cl-PANI/PVC composite films; Dehydrochlorination of PVC; In situ doping by UV; $\gamma$-Rays and e-beams

\section{Introduction}

Polyaniline (PANI), in its doped, conducting form (Emeraldine Salt, ES) is not soluble or processable when compared to its undoped, non-conducting form (Emeraldine Base, EB). Furthermore, some derivatives of PANI emeraldine base are highly soluble in common organic solvents. For example, 2-chloro-polyaniline (2-Cl/PANI) has more than one order of magnitude solubility in THF when compared with PANI, both prepared by the wellknown chemical routes [1,2]. Doping, however, is very important for tailoring the electronic properties of the resulting product. The conventional method of doping involves some harsh acid treatment either by wet and/or vapour techniques and alternative routes are highly desirable. In a previous work, we demonstrated that the electrical conductivity of PANI/PVC composite films can be drastically increased by exposure to $\gamma$-rays or UV radiation as a result of dehydrochlorination (loss of $\mathrm{HCl}$ ) of

\footnotetext{
"Corresponding author. Tel.: +90-312-266-4946; fax: +90-312-2664579; e-mail: bilchem@fen.bilkent.edu.tr
}

polyvinylchloride (PVC) and subsequent doping of the PANI by the in-situ-created $\mathrm{HCl}$ [3]. Dehydrochlorination of PVC is an unwanted process and has been well-studied especially under UV exposure [4-6]. In our case, however, we make use of this undesired property of PVC. Similar strategy was earlier followed by Ogun $[7,8]$ in his laminated polypyrrole/PVC films where photodehydrochlorination and doping with $\mathrm{I}_{2}$ or $\mathrm{FeCl}_{3}$ were employed; by Wan [9] in preparing transparent and conducting PANI/PVC coatings; by Ouyand and Chan [10] in preparing polypyrrole/PVC; and by Laska [11] PANI/PVC conducting films. In another recent study, it was reported that exposure to X-rays of the PANI in composite Langmuir-Blodgett films affected the electronic properties in a way similar to acid doping [12]. In the present study, 2-Cl-PANI/PVC composite films were exposed to various energetic particles and the changes were followed by spectroscopic techniques.

\section{Experimental}

The 2-Cl-PANI was prepared chemically by polymerising the freshly distilled monomer in a very strong acidic 
solution using $\left(\mathrm{NH}_{4}\right) \mathrm{S}_{2} \mathrm{O}_{8}$ as the oxidiser/initiator [1,2]. A stronger acidic medium $(5-6 \mathrm{M} \mathrm{HCl})$ was needed to obtain 2-Cl-PANI, whereas only $1 \mathrm{M} \mathrm{HCl}$ was necessary for PANI [13]. Subsequent reduction was achieved by treating the dried powder with $\mathrm{NaOH}$ or $\mathrm{NH}_{4} \mathrm{OH}$. The polymer was later dissolved together with PVC in THF which was also freshly distilled prior to use. The solubility of the 2-Cl-PANI(EB) in THF is much higher compared to PANI(EB) due most probably to the increased polarity and/or prevention of the parasitic polymer growth from the ortho-position [2]. The 2-Cl PANI/PVC composite films were prepared by codissolving the polymers in distilled THF and casting the solution into thin films on quartz (for UV-Vis-NIR) and $\mathrm{NaCl}$ windows (for IR) by evaporating the solvent under saturated THF atmosphere. The films obtained were about $10-50 \mu \mathrm{m}$ thick and uniform enough to obtain reproducible spectra. Similar films were also used for X-ray photoelectron spectroscopy (XPS) measurements.

XPS measurements were carried out on a Kratos ES300 electron spectrometer using $\mathrm{Mg} \mathrm{K} \alpha$ x-rays. UV-Vis-NIR characterisation was carried out with a Varian Cary 5E spectrophotometer and a Bomem MB102 spectrometer was used for Fourier transform infrared (FTIR) measurements. UV irradiation was achieved with a low-pressure Hg light source (UVP R-52G model, $\lambda=254 \mathrm{~nm}, 4.9 \mathrm{eV}$ ) and for the $\gamma$-ray exposure, a ${ }^{60} \mathrm{Co}$ source with varying doses (50-600 kGy) was used. The e-beam exposures were carried out with $7 \mathrm{MeV}$ electrons (0-500 kGy) at the University of Maryland linear accelerator at a dose rate of $0.3 \mathrm{~Gy} / \mathrm{s}$.

\section{Results and discussion}

Fig. 1 displays the UV-Vis-NIR spectra of the 2-ClPANI/PVC composite film after 15 and $30 \mathrm{~min}$ of UV exposure together with 5 min of further exposure to $\mathrm{NH}_{3}$ vapours. As-prepared composite blue film has an absorption band centred around $600 \mathrm{~nm}$ as well as the strong transition around $300 \mathrm{~nm}$ (similar to PANI) which is indicative of undoped form of the polymer (EB). The $600-\mathrm{nm}$ band shifts to longer wavelengths upon exposure to UV (as well as $\gamma$-rays and e-beams) and the films become green, indicative of the doped salt form (ES) $[2,14,15]$. Exposure to ammonia vapours brings the ES films back to its EB form. Electrical conductivity of the films also follows the optical pattern; undoped EB composite films have conductivities in the range of $10^{-6}$ $\mathrm{S} / \mathrm{cm}$ but the conductivity of the doped ES films can go up to $10^{-2} \mathrm{~S} / \mathrm{cm}$. We have not been able to observe any significant electrical or optical change of the 2-Cl-PANIonly powders upon exposure to the energetic particles or UV as opposed to the observations reported for the PANI-Langmuir-Blodgett films [12] and hence attribute this energetic particle-induced doping mainly to dehydrochlorination of PVC as was also claimed for PANI/PVC films [3]. Our argument is further supported by other spectroscopic findings. Fig. 2 shows the XPS spectra of 2-Cl-PANI/PVC films before and after exposure to $\gamma$-rays at a dose of $200 \mathrm{kGy}$. In addition to the strong $\mathrm{Cl} 2 \mathrm{p}_{3 / 2}$ peaks at $200.5 \mathrm{eV}$, which is assigned to chlorine bonded to carbon, a shoulder at $199.5 \mathrm{eV}$ develops after exposure to energetic particles which is not observed in 2-Cl-PANI-only

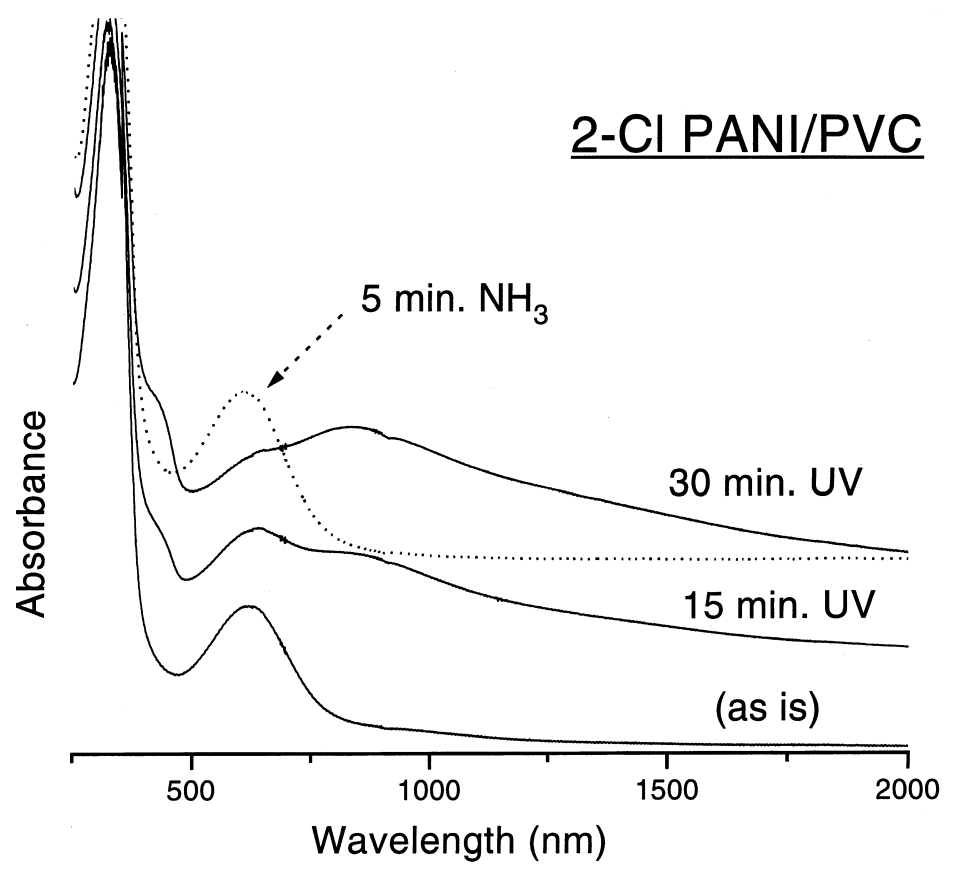

Fig. 1. UV-Vis-NIR spectra of 2-Cl-PANI/PVC composite films before and after 15 and 30 min exposure to UV and after further exposing them to 5 $\min$ of $\mathrm{NH}_{3}$ vapours. 


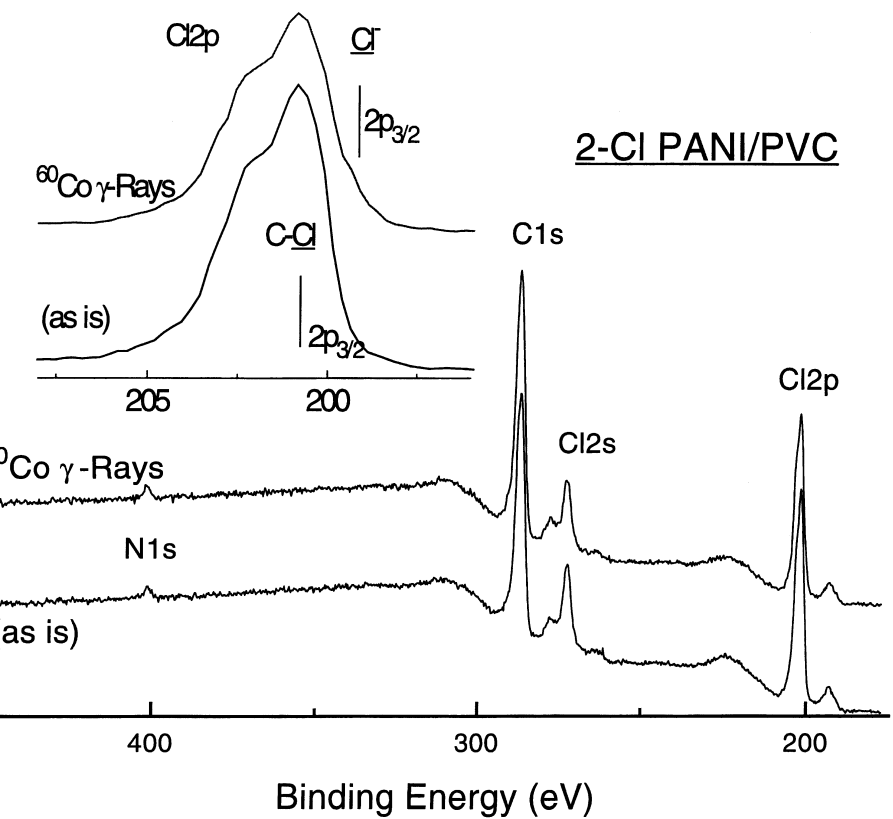

Fig. 2. XPS spectra of 2-Cl-PANI/PVC composite films before and after $200 \mathrm{kGy}{ }^{60} \mathrm{Co} \gamma$-rays exposure.

films. This shoulder is assigned to chloride ion $\mathrm{Cl}^{-}$and strongly supports the dehydrochlorination of the PVC as the reason for doping of the EB films $[3,16,17]$. In Fig. 3, FTIR spectra of the 2-Cl-PANI/PVC films are shown as a

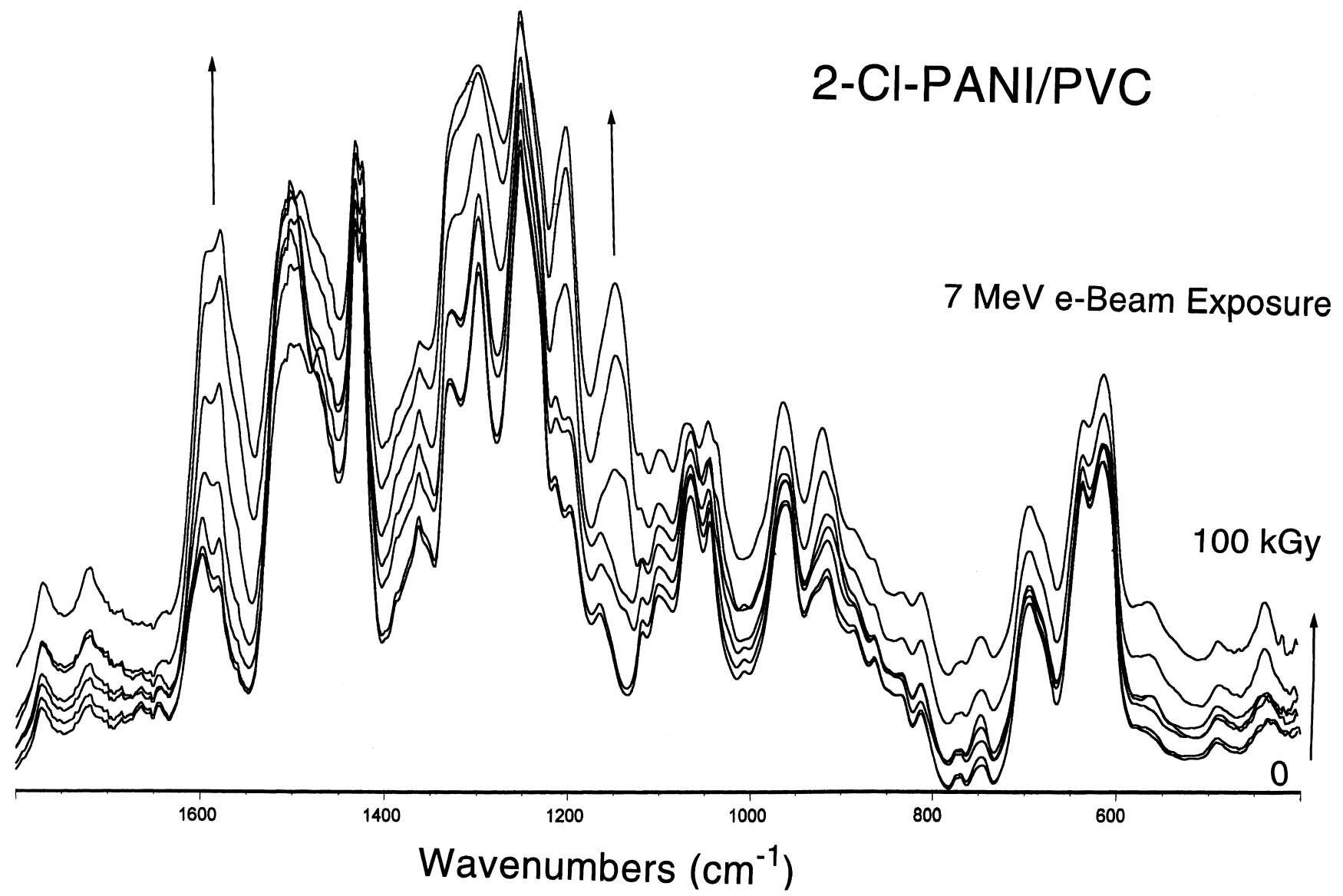

Fig. 3. FTIR spectra of 2-Cl-PANI/PVC composite films before and after exposure to $7 \mathrm{MeV}$ e-beams. 


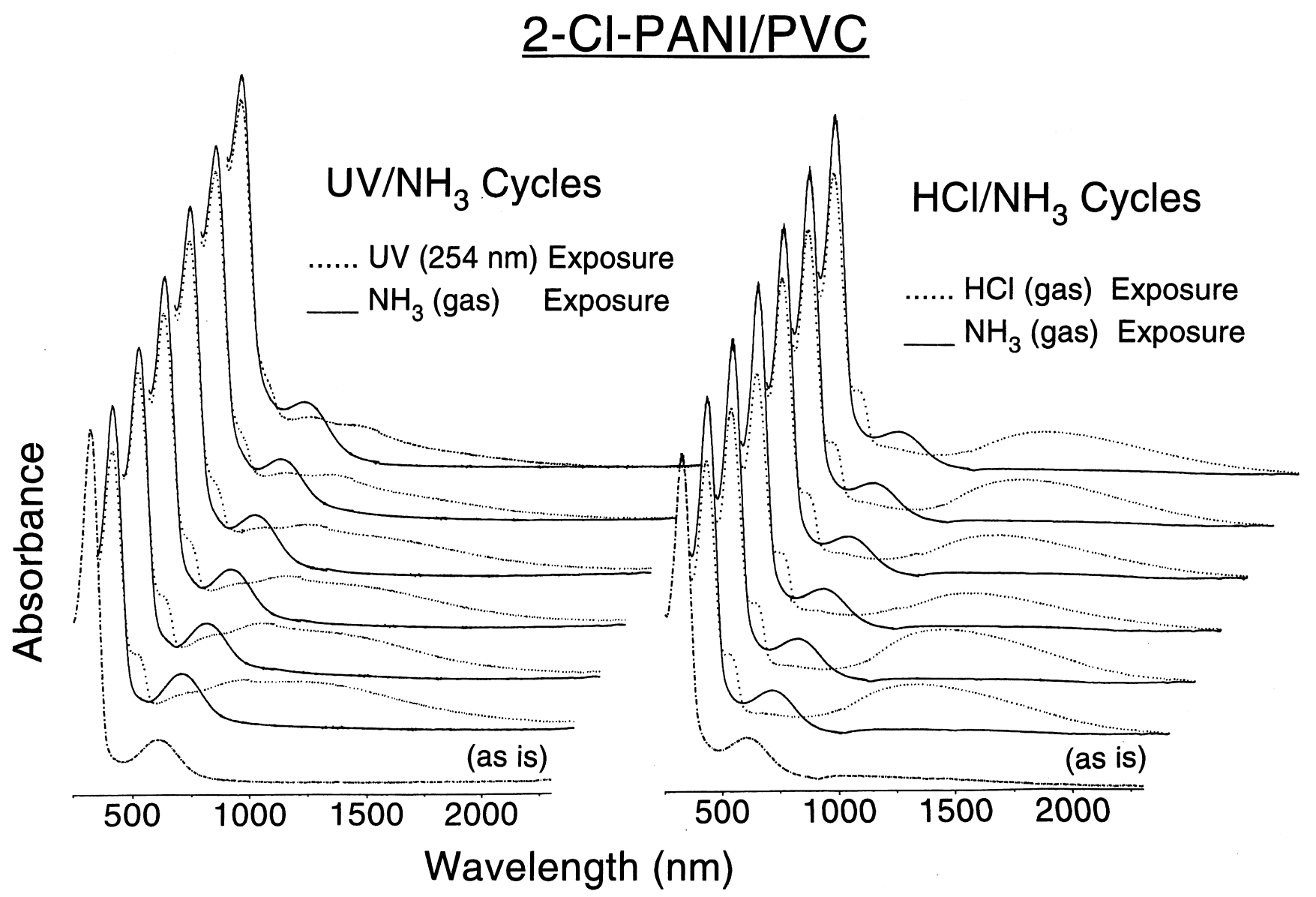

Fig. 4. UV-Vis-NIR spectra of the 2-Cl-PANI/PVC composite films exposed to UV $/ \mathrm{NH}_{3}$ and $\mathrm{HCl} / \mathrm{NH}_{3}$ cycles.

function of e-beams exposure. Here again, increased absorbance of the bands around 1600 and $1160 \mathrm{~cm}^{-1}$ is indicative of doping $[2,3,14,18,19]$. The overall process can be described as follows:

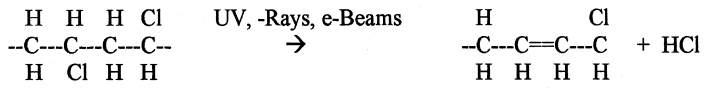

$\mathrm{HCl}+2$-Cl-PANI(EB, blue $) \rightarrow$ 2-Cl-PANI(ES, green $)$

It is also possible to dope the EB films by direct exposure to $\mathrm{HCl}$ vapours. Fig. 4 shows the $\mathrm{UV} / \mathrm{NH}_{3}$ and the $\mathrm{HCl} / \mathrm{NH}_{3}$ cycles. The UV doping process eventually dies off as more and more $\mathrm{HCl}$ are removed from the PVC matrix.

\section{Conclusions}

As a continuation of our previous work on PANI/PVC composite films, we demonstrated that exposure to energetic particles induces doping which can also be reversed to a certain degree. Since the conducting polymer is embedded into the PVC matrix, the measured electrical con- ductivities are low (in the range of $10^{-3}-10^{-2} \mathrm{~S} / \mathrm{cm}$ ) for both energetic particle or UV and gaseous $\mathrm{HCl}$-exposed films compared to the conductivities of usual conducting polymers. However, this completely solvent-free novel process can still be useful in several applications like dosimetry, radiation monitoring or on/off devices under irradiation environment, etc.

\section{Acknowledgements}

We thank Prof. J. Silverman of the University of Maryland for providing access to the linear accelerator facility. This work was partially supported by TUBITAK, the Scientific and Technical Research Council of Turkey, through the grant TBAG-COST/1 within the context of COST 518 Action of the European Community.

\section{References}

[1] J.C. Chiang, A.G. McDiarmid, Synth. Met. 13 (1986) 133.

[2] T.A. Skotheim, R.L. Eisenbaumer, J.R. Reynolds (Eds.), Handbook of Conducting Polymers, 2nd edn., Marcel-Dekker, New York, 1998.

[3] U.A. Sevil, O. Guven, S. Suzer, J. Phys. Chem. B 102 (1998) 3902. 
[4] E. Owen, Degradation and Stabilization of PVC, Elsevier, London, 1984.

[5] W. Schnabel, Polymer Degradation, Macmillan, New York, 1985.

[6] D. Braun, E. Bezdadea, Theory of Degradation and Stabilisation in Encyclopedia of PVC, 2nd edn., Marcel-Dekker, New York, 1989.

[7] K. Ogun, J. Appl. Polym. Sci. A 32 (1994) 33.

[8] K. Ogun, J. Appl. Polym. Sci. A 33 (1995) 1375.

[9] M. Wan, Thin Solid Films 259 (1995) 188.

[10] M. Ouyand, C.M. Chan, Polym. Eng. Sci. 36 (1996) 2676.

[11] J. Laska, Synth. Met. 84 (1997) 117.

[12] J.A. Malmonge, A. Dhanabalan, A. Riul Jr., R.M. Faria, O.N. Oliveira Jr., Synth. Met. 101 (1999) 801.
[13] W. Shenlong, W. Fosung, G. Xiaohui, Synth. Met. 16 (1986) 99.

[14] J.L. Bredas, G.B. Street, Acc. Chem. Res. 18 (1985) 309.

[15] B. Wessling, Synth. Met. 85 (1997) 1313.

[16] E.T. Kang, K.G. Neoh, K.L. Tan, Prog. Polym. Sci. 23 (1998) 277.

[17] W.R. Salaneck, I. Lundstrom, B. Ranby (Eds.), Conjugated Polymers and Related Materials; Proc. 81st Nobel Symp., Oxford Univ. Press, New York, 1993.

[18] Y. Frukawa, T. Hara, Y. Hyodo, I. Harada, Synth. Met. 16 (1986) 189.

[19] S. Stafstrom, J.L. Bredas, A.J. Epstein, H.S. Woo, D.B. Tanner, W.S. Huang, A.G. MacDiarmid, Phys. Rev. Lett. 59 (1987) 1464. 